\title{
LUÍS CARDOSO: de escravo a homem de negócio da Praça do Recife (XVII e XVIII)
}

\author{
Janaína Santos Bezerra*
}

RESUMO: O presente artigo consiste em relatar e problematizar a trajetória de vida e ascensão de Luís Cardoso, um pardo, natural de Pernambuco, que viveu a moda da nobreza mesmo tendo passado pela árdua experiência do cativeiro. Aqui temos a pretensão de observar as estratégias usadas por tal indivíduo em sua atuação social, política e econômica. Logo, a intenção proposta não se esgota no indivíduo, mas busca traçar um panorama das hierarquias sociais em Pernambuco, no século XVIII, através de tal trajetória, bem como, de todo um quadro de exclusão dela resultante.

PALAVRAS-CHAVE: Pardo; Ordem Terceira; Inserção; Elite.

\section{Luís Cardoso: from slave to business man from Recife Square (XVII and XVIII)}

ABSTRACT: The present article consists in reporting and problematizing the life and ascension trajectory of Luís Cardoso, a native of Pernambuco, who lived the fashion of the nobility even though he went through the arduous experience of the captivity. Here we have the pretension to observe the strategies used by such individual in his social, political and economic performance. Therefore, the proposed intention is not exhaustive in the individual, but seeks to draw a panorama of social hierarchies in Pernambuco in the eighteenth century, through such a trajectory, as well as a whole picture of exclusion resulting therefrom.

KEYWORDS: Pardo; Third Order; Insertion; Elite.

\section{Luís Cardoso: de esclavo a hombre de negocios de la plaza de Recife (XVII y XVIII)}

RESUMEN: El presente artículo consiste en informar y problematizar la trayectoria de vida y ascensión de Luís Cardoso, nativo de Pernambuco, que vivió a la manera de la nobleza a pesar de que pasó por la ardua experiencia del cautiverio. Aquí tenemos la pretensión de observar las estrategias utilizadas por dicho individuo en su desempeño social, político y económico. Por lo tanto, la intención propuesta no es exhaustiva en el individuo, sino que busca trazar un panorama de las jerarquías sociales en Pernambuco en el siglo XVIII, a través de tal trayectoria, así como una imagen completa de la exclusión resultante de ello.

PALABRAS CLAVE: Pardo; Tercera Orden; Inserción; Elite.

\footnotetext{
*Doutora em História pela Universidade Federal de Pernambuco. Atualmente é docente da Rede Estadual de Pernambuco. Contato: Av. Afonso Olindense, 1513, Várzea, CEP: 50810-900, Recife-PE, Brasil. Email: janatabira@hotmail.com. ORCID: https://orcid.org/0000-0003-3425-9590.
} 
Em Pernambuco, muitos pardos ${ }^{1}$, através de diversas estratégias de inserção, souberam manejar uma estrutura aparentemente rígida e extrair dela certas regalias, sem, no entanto, ameaçar frontalmente o sistema. A dinâmica do espaço colonial permitiu a diversos sujeitos, até então excluídos por sua cor, uma mobilidade social ascendente e, consequentemente, uma maior visibilidade social. Porém, mesmo ocupando posições de prestígio na sociedade colonial pernambucana, tais indivíduos tiveram que conviver com as restrições decorrentes de uma sociedade excludente. Em resposta, alguns tiveram que se pronunciar perante a Coroa Portuguesa na perspectiva de fazer valer os seus direitos. Para a maioria, os "andarilhos da sobrevivência, sozinhos ou com a família", a mobilidade espacial era "um dos poucos recursos que lhes restava numa terra de fronteiras" ${ }^{2}$. O fato é que, através de acúmulos de bens, clientelismo, concessão de mercê, entre outras estratégias, muitos pardos acabaram rompendo as barreiras impostas e se tornaram parte integrante de uma elite.

Aqui vamos relatar apenas um caso, dos muitos que foram registrados em Pernambuco. A distinção por cor no espaço colonial pernambucano gerou constantes conflitos. Era corriqueiro o envio de requerimentos de sujeitos pardos que solicitavam providências junto à Coroa, em meio a frequentes restrições. Foi assim que se processou com o pardo Paulo Coelho, no ano de 1754. O mesmo suplicou a D. José I provisão para que sua cor parda não lhe servisse de impedimento para exercer qualquer função pública em qualquer parte do Brasil ${ }^{3}$. Paulo Coelho residia em Pernambuco e exercia o ofício de escrivão público do judicial há mais de vinte anos. O mesmo executava muito bem o seu ofício, sendo frequentemente procurado por outros escrivães para tirar dúvidas provenientes do próprio ofício, agradando a todos sem distinção.

Pelo bom serviço apresentado foi nomeado para servir de inquiridor, contador e distribudor nos impedimentos de José de Araújo Viana. Diante de tal fato, o pardo Paulo Coelho solicitou provisão junto à Coroa, suplicando que o seu "acidente da cor parda" não fosse tomado como impedimento na ocupação de qualquer ofício da república. Paulo Coelho se mostrou um fiel vassalo do rei. Além de ocupar cargo da república, também servia às tropas militares com patente de capitão na infantaria de Ordenança. Em tal posição, o mesmo seguia os passos do seu pai, o sargento-mor Paulo Coelho, que também havia servido às tropas pardas em Pernambuco ${ }^{4}$.

O fato é que Paulo foi um, entre tantos outros mestiços, que se fez notável nas possessões ultramarinas portuguesas. Como um bom letrado e oficial militar soube desempenhar bem o seu papel, ao mesmo tempo em que não se rendeu às restrições impostas. 
Assim como Paulo, Luís Cardoso, forro, também teve que lidar com os preconceitos que recaíam sobre a sua cor parda. A sua trajetória de vida nos chamou atenção. Nas linhas que se seguem buscamos elucidar alguns contratempos que envolveram a sua pessoa e autoridade colonial, destacando as estratégias utilizadas por ele na perspectiva de se afirmar no espaço colonial pernambucano.

\section{Da nobreza à elite pernambucana}

Antes de darmos início a uma abordagem sobre a trajetória de Luís Cardoso, faz-se necessário um breve esclarecimento sobre uma das divisões básicas que se fazia entre os indivíduos na sociedade lusitana, em Portugal e, por conseguinte, na América portuguesa.

Segundo Raimundo Pessoa, os membros de tais sociedades eram divididos em, pelo menos, duas categorias básicas: a nobreza, formada por todas aquelas pessoas que podiam, teoricamente, dependendo das habilidades e ofícios aprendidos, ocuparem qualquer cargo ou função, tanto nos quadros régios, quanto na Igreja Católica, e auferir com isso certos privilégios; e a plebe, composta por todos aqueles que não podiam acessar tais funções e privilégios. Segundo o autor, na sociedade portuguesa, a plebe se compunha de judeus, de mouros, de cristãos novos, de ciganos e de toda a sorte de mecânicos. Porém, com o tempo, o advento da escravidão negra fez surgir mais alguma sorte de gente igualmente inabilitáveis: negros e todos aqueles que carregavam a pecha do servilismo ${ }^{5}$.

Segundo Raphael Bluteau, os nobres eram aqueles que "por sangue ou alvará de príncipe, diferenciam-se em honras e estimação dos plebeus e mecânicos" ${ }^{\prime 6}$. Sobre a composição de tal nobreza, Ângela Xavier e Hespanha ressaltam a existência de dois tipos: a "natural" e a "política". Na primeira, incluía-se o príncipe, os nobres e seus filhos. Por ser natural, essa nobreza também era generativa, ou seja, transmissível por geração. Por outro lado, a nobreza política era decorrente, não da natureza, mas de normas de direito positivo, dos costumes da cidade. "Deste tipo é a nobreza que se obtém pela ciência, pela milícia, pelo exercício de certos ofícios, pelo privilégio e pelo decurso do tempo"7. Logo, "a nobreza era entendida como uma virtude essencialmente natural [....] quer essa natureza seja uma disposição familiar, transmissível pelo sangue, quer seja a reputação ou fama que objetivamente decorre do exercício de certas funções sociais" ${ }^{\prime}$. Mas, para as manterem, era uma condição aos indivíduos em ambas as nobrezas viverem “à lei da nobreza”, isto é, permanecerem juntamente com o núcleo familiar em estado de limpeza de sangue e mãos, ${ }^{9}$ ou seja, longe de toda atividade vil, cercados de serviçais e riquezas. 
Segundo George Cabral, para a Coroa parecia interessante a criação de uma "nobreza política" cuja participação no governo municipal permitisse o engrandecimento das famílias, tal qual se fazia com a nobreza natural por intermédio da hereditariedade ${ }^{10}$. João Fragoso complementa que a montagem da produção colonial se processou dentro dos cenários do Antigo Regime; esse movimento, simultaneamente, criaria "uma nobreza da República" cujas bases eram o mando político e a apropriação daquilo que o mesmo denominou "economia do bem comum". Para o autor, essa economia seria formada por bens e serviços sob a jurisdição do Senado e do rei, porém administrados por poucos eleitos, mas custeados por todos os colonos. "Tal quadro, por decorrer do controle da política e se traduzir numa acumulação econômica excludente, se decidia na disputa política e se assentava em vastas redes de parentesco e de clientela"11. Porém, lembra o autor, que aquela nobreza e suas práticas, como fenômenos majoritários, em algum momento da história colonial cederia espaço para outras relações sociais. Tendo em vista que, em finais do século XVIII, a elite econômica era formada pelos comerciantes de grosso trato, no entanto, a prática da exclusão social, para além da população cativa, continuaria como uma das chaves para a acumulação de riquezas ${ }^{12}$.

Ao que parece, a composição da nobreza na América portuguesa se mostrou complexa e diversificada. $\mathrm{O}$ seu corpo estrutural não apenas foi formado por nobres de sangue, esses muito poucos, de caráter hereditário, mas também por agentes que através de serviços prestados à Coroa, foram contemplados com mercê. Logo, ser nobre significava "ter um emprego de distinção e honra e, quando ligado à terra, possuir estimados cabedais e viver à moda da nobreza. O título nobiliárquico, propriamente dito, não era o aspecto mais importante, as condições para ostentação do estado de nobreza, sim”. Nesse sentido, o que contava "não era a ostentação do título, mas a capacidade de mostrar que se vivia em estado de nobreza". Em uma sociedade "repleta de negros cativos, gentios e outras castas de gente vil e sem posses, exibir-se com distinção, era quase um imperativo para todos aqueles que queriam ser tidos e havidos por estimados"13.

$\mathrm{Na}$ verdade, nobreza e riqueza não se conjugaram na sociedade colonial portuguesa. Aqueles que conseguiram se firmar na nobiliarquia foi porque formalizaram as honras por meio de instrumentos de nobilitação, ou seja, como a obtenção de foros de fidalgo da Casa Real, cargos na câmara, hábitos das ordens militares, postos da oficialidade nas ordenanças, dentre outros ${ }^{14}$.

Para citar um exemplo corrente na sociedade pernambucana setecentista, o pardo Luís Nogueira de Figueiredo, filho de um branco principal da terra, incorporou bem o papel de 
nobre. O mesmo procurou viver a "lei da nobreza" com limpeza de mãos. Viveu dos bens deixados por seu pai. Além disso, foi oficial de milícia e foi habilitado na Ordem de Santiago. Isso significa dizer que, não obstante os valores de Antigo Regime, indivíduos, instituições, e grupos não eram imóveis ${ }^{15}$.

Fernanda Olival e João Rêgo, ao se referirem à região de Cabo Verde, ressaltam que em decorrência das incongruências e dificuldades do sistema, no início do século XVII, os "filhos da terra", ou seja, mulatos e negros, ocupavam os espaços sociais anteriormente preenchidos pelos reinóis, de quem muitos deles eram descendentes ilegítimos. Para os autores, tratava-se de uma nova elite, essencialmente urbana e cosmopolita. Um exemplo foi o mulato André Álvares que recebeu a mercê do hábito da Ordem de Cristo, apesar de ser mestiço, em troca dos seus serviços na defesa da Ilha. Em Cabo Verde a terceira elite geracional que cronologicamente coincidia com a segunda metade do século XVII, era endógena, mestiça e, claramente, de matriz cabo verdiana. "Formavam-na os chamados 'brancos da terra' (maioritariamente mulatos e pretos), o que levou o governador Juzarte de Santa Maria a reconhecer, em 1749, que 'os desta ilha que têm este nome de brancos e não o são" ",16.

Segundo tais pesquisadores, em outros territórios do Atlântico, onde a percentagem da população de origem africana era elevada, a situação não era diferente ${ }^{17}$. Logo, a adoção do referido conceito de nobreza ao longo do século XVI criou uma zona de fluidez na hierarquia social constituída nas conquistas. Nesse caso, "não era difícil a um filho de lavrador sugerir que seus pais se tratavam à lei da nobreza, com bestas e criados". Embora a mobilidade social fosse, como em todas as sociedades dominantemente agrárias, quantitativamente limitada, essa zona de fluidez podia potenciar, em determinadas condições e conjunturas, a oportunidade para rápidos processos de ascensão social ${ }^{18}$. visão de Russell Wood, "a aplicabilidade do conceito de pirâmide às sociedades escravocratas do Novo Mundo, uma pirâmide cuja ampla base se compusesse de escravos e cujo topo estivesse reservado à aristocracia ou à nobreza mercantil e de proprietários de terras, deve ser aceita com cautela ${ }^{19}$. No caso brasileiro, argumenta o autor, dois pontos devem ser observados: "o primeiro é a inferência de rigidez; apesar da constante representada pela escravidão, nada estaria mais longe da verdade", com relação à sociedade do Brasil, onde havia grande mobilidade vertical e horizontal e onde existiam drásticas variações regionais de composição social. Não menos fundamental era o fator cronológico: a sociedade do primeiro século de colonização diferia marcadamente daquela de dois séculos depois. "O segundo 
motivo de cautela relaciona-se à composição da pirâmide social e aos critérios para determinar a posição de um indivíduo"20.

Para o autor, o Brasil possuía sua própria dinâmica interna de "evolução, revolução ou retrocesso". A sociedade passava por mudanças e conflitos que davam origem a uma descontinuidade $^{21}$. Logo, “é inevitável que a formação de uma composição específica para o indivíduo de ascendência africana na América portuguesa corra o risco de distorcer a realidade". Segundo o autor, observar a sociedade constituída na conquista portuguesa da América a partir do potencial de flexibilidade e variedade, sem esquecer o resultante grau de harmonia ou conflito, pode gerar um retrato mais realista da posição dos libertos na colônia do que a aplicação do modelo da pirâmide ${ }^{22}$. A rigidez hierárquica cedeu espaço para uma dinâmica social no espaço colonial.

Em Pernambuco, muitos pardos, através de diversas estratégias de inserção, souberam manejar uma estrutura aparentemente rígida e extrair dela certas regalias, sem, no entanto, ameaçar frontalmente o sistema.

A elite aqui abordada exprime de forma não monótona o seu poder social. O que significa afirmar que "os seus sinais distintivos, a sua visibilidade, as suas formas de hegemonia, os tipos de dependências que suscitam são muitos diversos, não podendo reduzirse a um modelo único"23. A nomeação de oficiais, por mais restrita que fosse, vinha ao encontro das estratégias de mobilidade social e, consequentemente, de tentativa de supressão do estigma do cativeiro ${ }^{24}$.

\section{Luís Cardoso: egresso da escravidão}

O pardo Luís Cardoso nasceu por volta do ano de 1655, em terras pernambucanas. Era filho de uma mulata de nome Simoa, escrava de Manoel da Costa de Moura. Após a morte do seu proprietário, Luís passou a servir a um dos seus herdeiros, o capitão Manoel de Barros Maduro, casado com a filha de seu Manoel, Dona Ana Coutinho de Azevedo. Maduro havia assegurado que daria a liberdade a Luís por $40 \$ 000$ réis, promessa que foi cumprida pela viúva, sua mulher, em 1667, quando o menino contava com uns doze anos de idade. Tal quantia foi proveniente de esmolas que lhe deram os fiéis para a sua liberdade, como ficou registrado em carta ${ }^{25}$.

Recife começou uma nova vida, agora como um homem forro. Foi empregado em uma loja do comerciante Cristiano Paulo, tendo sido, em princípio, confundido como escravo da loja. O que demonstra o quanto eram visíveis em sua tez os liames da escravidão. Por volta de 
1687, por confiança do seu patrão, passou a assumir a loja, em decorrência do deslocamento de Cristiano Paulo para o campo, onde pretendia viver uma vida rural de senhor de engenho ${ }^{26}$. Com o tempo, Cardoso ganhou experiência com os negócios, passando a lidar com quantias cada vez maiores, o que contribuiu de forma positiva na multiplicação das suas finanças. No princípio comercializou açúcar, porém o câmbio foi tão intenso que agregou também outros negócios, como a comercialização de tabaco e escravos, que eram realizados na Costa da Mina e em Angola, revendendo escravos que recebia não apenas do Recife, mas do Rio de Janeiro e Bahia.

Luís Cardoso pode ser aqui citado como um homem pardo que ascendeu socialmente de uma forma muito rápida. $\mathrm{O}$ mesmo passou de escravo a grande comerciante da Praça do Recife. No comércio usufruiu de conforto, adquirindo também alguns imóveis como uns "sobrados na rua da cadeia velha, por detrás da matriz do Corpo Santo, avaliado em $2: 440 \$ 000 "$ ". Os objetos de seu interior, levantados no inventário, indicam que Cardoso, "levara uma vida frugal; alguns quadros pequenos, roupa de cama e mesa, travesseiros, material de escritório, objetos de cozinha". Entre as suas manias adorava frutas confeitadas e chocolate, usava chapéu de sol e criava canários contadores ${ }^{27}$.

Além do comércio, Cardoso também viveu da prática de empréstimos, cujos juros eram de 6,25\% ao ano. Muitos homens de negócio da Praça do Recife fizeram uso dos serviços oferecidos por Cardoso, não apenas na obtenção de empréstimos, como também na compra de escravos. Um exemplo foi o comerciante Cristóvão Vieira de $\mathrm{Melo}^{28}$.

O fato de ser pardo ser oriundo do cativeiro, não serviu de impedimento em sua admissão na Ordem Terceira de São Francisco do Recife ${ }^{29}$. É certo que em tal instituição não era permitida a entrada, de homens de cor de sujeitos com defeito mecânico e muito menos oriundos da escravidão. No caso de Luís, os defeitos eram de conhecimento de todos, porém o fato de ser um homem de grande cabedal e doador de exorbitantes quantias na Ordem pode ter servido como fator motivador da sua admissão e abrandado debates sobre sua baixa qualidade. Isso mostra a possibilidade de flexibilidade das regras, muitas vezes decorrente da disponibilidade de recursos financeiros abundantes dos interessados. Segundo João Alfredo dos Anjos, a sua aceitação na ordem não se deu por acaso, mas mediante contribuições e doações em dinheiro ou no abatimento de dívidas de terceiros. Sobre o fato, João Cabral de Melo lembra que, apesar da sua admissão à Ordem dos Terceiros, seu nome não constou nas pautas dos cargos de ministro, síndico ou secretário da Irmandade, provavelmente por conta do requisito de "limpeza de sangue", indispensável para ocupar o topo da hierarquia dos 
dirigentes da Mesa da associação religiosa. O fato de portar "defeito de raça infecta" foi, certamente, agravada pela especificidade de seu "defeito mecânico", "que remontava ao trabalho escravo, passando posteriormente pela condição subalterna de vínculo de dependência com o mercador alemão no exercício das atividades de caixeiro, ou de mascate".

O fato é que Cardoso não foi apenas irmão da Ordem Terceira de São Francisco, foi também sacristão em 1721. Foi nesse mesmo ano que Cardoso fez a sua maior doação em vida à Ordem Terceira de São Francisco do Recife. A quantia foi de 10 mil cruzados ou cerca de 4:000\$000 (quatro contos de réis). No biênio 1723/24, tornou-se definidor, cargo de mais prestígio da mesa regedora da instituição, e que havia sido ocupado na criação da ordem por Antônio Fernandes de $\operatorname{Matos}^{30}$, rompendo com as desconfianças e impedimentos velados anteriores. Desde pelo menos 1716, Cardoso passou a dar esmolas e fazer doações à Ordem. Nesse ano foram doados 4\$000. A entrada de Cardoso na instituição se deu em 12 de fevereiro de 1719 e, cumprindo o ano de noviciado, recebeu a profissão em 13 de fevereiro de 1720. Por esse tempo era já um comerciante reconhecido, rico e estável, contando com aproximadamente 65 anos. Ao fim de sua escalada social, Cardoso veio alcançar a posição de mercador de grosso trato, admitida como dignificante" 31 .

O mesmo morreu na cidade de Olinda, no ano de 1724, como definidor da Ordem terceira de São Francisca, a qual nomeou como sua testamenteira, seguida das irmandades da Madre de Deus e do Carmo. Cardoso foi enterrado no convento de Santo Antônio com o hábito de São Francisco. O seu cortejo fúnebre foi grandioso e contou com a presença das irmandades que a tinham como irmão. Em testamento, Cardoso declarou que era natural do Recife, não tinha lembranças dos seus pais naturais, que tinham morrido quando ainda era criança. Era solteiro e não teve filhos. Porém, segundo o testamento, teve que responder vários processos de determinação de paternidade, compreensíveis pela fortuna que havia acumulado. Em todos teve sentença favorável. Ao seu testamento Cardoso anexou, além dessas sentenças, a sua carta de alforria. Não sabemos ao certo se a preocupação em anexar tais documentos foi algo proveniente de Cardoso ou da própria Ordem, na preocupação de evitar perdas financeiras, caso algum sujeito se pronunciasse como filho e herdeiro de Cardoso. Como foi o caso de José Gomes Cardoso que, em 1738, através de uma provisão, apelou contra a Ordem Terceira de São Francisco do Recife, testamenteira e herdeira das finanças do seu falecido pai.

Em documento, José Gomes Cardoso demonstrou sua insatisfação perante a tal instituição religiosa que se negava a transferir qualquer recurso financeiro referente à herança 
deixada por Luís Cardoso, que se achava em posse da dita Ordem. Afim de ser atendito em suas súplicas, José Gomes Cardoso apresentou "provas por documentos autênticos” e, perante a justiça colonial, colocou-se como um "orfão pobre" e "universal herdeiro do seu pai". Segundo José, a Ordem Terceira de São Francisco havia se apossado do valor de “24:116\$610( vinte e quatro contos, cento e dezesseis mil, seiscentos e dez réis)”. Além da apropriação do dinheiro, a instituição religiosa, com ousadia, também havia declarado nulo o testamento comprobatório de filiação, que era público e notório na cidade.

Segundo o suplicante, a filiação era tão notória que até os irmãos da mesa reconheceram. Para José, a intenção da Ordem Terceira era inibir as ações de reconhecimento de sua filiação que, consequentemente, lhes trariam prejuízos financeiros. De acordo com a sua denúncia, a instituição religiosa, juntamente com o governador de Pernambuco, havia exilado o suplicante no reino de Angola. Tal ato teria ocorrido acompanhado de violência, mesmo o suplicante não tendo nenhuma "culpa, nem delito pelo seu bom procedimento". José temia em perder a própria vida ao apelar a sua parte da herança deixada pelo pai, que se encontrava sob a guarda da "poderosa” Ordem Terceira de São Francisco do Recife ${ }^{32}$.

De fato, Luís Cardoso havia deixado para Ordem Terceira de São Francisco alguns bens. Em seu inventário, no verso da folha 51, "se acha somada a fazenda inventariada, que importa esta 24:116\$010, cuja fazenda inventariada foi parte dinheiro, ouro, prata, móveis, escravos e dívidas" que se devia ao defunto testador, além de moradas de casas. Em documento consta a Ordem Terceira de São Francisco do Recife como a primeira beneficiada de tais bens ${ }^{33}$.

Um ano após o ocorrido, em 1739, o governador de Pernambuco, Henrique Luís Pereira Freire de Andrada, enviou uma carta ao rei, D. João V, fazendo queixas a José Gomes Cardoso por ter lhe entregue uma provisão aberta. Segundo o governador, tal ato não traria boas consequências, pois abrindo os despachos da Coroa "se são a seu favor, os apresentam, e se não, os guardam"34.

Nas palavras do governador, fica evidente que era corriqueira a violação de documentos reais, no espaço colonial pernambucano. Para evitar qualquer tipo de constrangimento, o governador apelou, junto à Coroa, que a documentação enviada fosse acompanhada de uma segunda via, o que evitaria fraudes e desaparecimento de documentos ${ }^{35}$. O fato do despacho apresentado por José não estar fechado deixava dúvidas sobre a autenticidade do documento, ao mesmo tempo que colocava em risco a índole do suplicante. José estava tratando de assuntos relacionados a questões financeiras que, por outro lado, 
envolviam uma grande instituição religiosa da época, que era a Ordem Terceira de São Francisco do Recife. A todo instante ele teria que se deparar com opositores, inclusive o governador, que bem provavelmente era irmão da Ordem. Ganhar a herança significaria uma grande perda econômica para tal instituição religiosa e, consequentemente, para a elite pernambucana que lá estava associada.

A Ordem Terceira de São Francisco ganhou a causa, anulando assim as provas de filiação do suplicante. Diante dos fatos, José Gomes Cardoso apelou novamente junto à Coroa no ano de 1740, argumentando que teria sido prejudicado no caso, por não ter como juntar provas por ter sido mandado para Angola, sem justa causa. O mesmo escreveu um requerimento ao rei D. João $\mathrm{V}$, pedindo provisão para poder apelar da sentença proferida pelo ouvidor da capitania de Pernambuco, Antônio Rebelo Leite, para a Casa da Suplicação ${ }^{36}$. Infelizmente não localizamos documentos posteriores ao ano de 1740 que retratem o caso, porém é notória a força e a influência que a Ordem Terceira de São Francisco tinha no espaço colonial pernambucano.

A Ordem Terceira de São Francisco era uma instituição constituída pela elite colonial. Segundo Caio Boschi, a admissão em tal instituição era extremamente mais seletiva que nas irmandades, tanto no que concernem aos quesitos para a candidatura, quanto ao processo de sindicância, para não mencionar o ritual de profissão. Para o autor, via de regra, as Ordens Terceiras se caracterizavam por serem associações das camadas elevadas, sendo a composição do seu quadro social mais sofisticada ${ }^{37}$. No caso de Luís Cardoso a sua participação em instituições religiosas não ficou restrita apenas à Ordem Terceira de São Francisco. O mesmo também foi membro integrante de outras instituições religiosas como: a Irmandade do Santíssimo Sacramento, a de Nossa Senhora do Rosário, a de Santa Luzia, de Santa Catarina e a do Bom Jesus das Portas. O que serve como indicativo do seu prestígio e poder econômico.

Ao analisarmos a documentação da irmandade do Santíssimo Sacramento do Recife, não conseguimos localizar indícios referentes a qualquer restrição de cor dos associados, porém o compromisso deixa claro que os pretendentes teriam que "ser tal qual pela sua qualidade e costume não a deslustre e inquiete" ${ }^{\text {"38 }}$. Ao se associar na Irmandade do Santíssimo Sacramento do Recife, Luís Cardoso teve que arcar com uma quantia elevada de entrada, no valor de 20\$000,00(vinte mil réis), assim como estava estabelecido no compromisso, quantia essa restrita apenas aos mais abastados de bens ${ }^{39}$. $\mathrm{Na}$ irmandade do Rosário dos Homens pretos do Recife o mesmo teve que pagar o valor de $2 \$ 000$, quantia esta paga pelos homens pardos que desejassem fazer parte da instituição do Rosário. Assim como 
também teve que arcar com anuidades no valor de $\$ 160$ réis, destinadas aos "sufrágios pelos irmãos mortos", sendo colocadas de forma separada no cofre da dita irmandade do Rosário ${ }^{40}$. O que mostra que o enterro de Luís Cardoso foi, de fato, grandioso levando em conta o quantitativo de associações religiosas que ele fez parte.

O fato de Luís Cardoso ter feito parte da Ordem Terceira de São Francisco do Recife, mesmo sendo forro, pardo e possuidor do defeito mecânico, indica seu alto poder econômico. Ao observar o livro das pessoas negadas na Ordem de São Francisco do Recife é possível perceber que eram examinadas as informações sobre a ascendência familiar, a disponibilidade de recursos financeiros e a reputação social daqueles que desejavam fazer parte da instituição. Nas prerrogativas de admissão não podiam fazer parte da ordem os pretendentes que tinham sangue judeu, mulato, mouro ou de nenhum outro povo "infecto" desde a geração dos seus avós; deviam ter reputação moral ilibada, sem nenhum processo civil, eclesiástico ou do Santo Ofício; e ainda boa conduta e recursos financeiros abundantes para socorrer a Ordem. Os candidatos também não deveriam ser muito jovens nem muito velhos para arcar com as despesas de seus funerais. Não podiam exercer "ofício vil" ou trabalho manual, não podiam ser membros de outras Ordens Terceiras, nem terem sido expulsos de alguma delas. Diversas pessoas tiveram seu acesso negado na instituição pelo fato de terem a "casta de pardo ou mulato". Aqui podemos citar: Antônio Gregório da Luz, Antônio Pereira de Melo, Ana Maria da Silva, Antônia de Mendonça Freire, Ana Maria da Conceição, Antônio José Pereira Muniz, Antônio de Sousa Reis ${ }^{41}$, Felipe de Freitas, Francisco Rodrigues Barbosa, Florência de Oliveira $^{42}$, dentre tantos outros. Muitas vezes não se tinha nem conhecimento de fato das origens do pretendente. Como foi o caso de Cosme Afonso, exposto em casa de Domingos Afonso Casa Nova, irmão da Ordem de São Francisco, que não foi admitido na Ordem por constar em informação que o mesmo não era branco legítimo ${ }^{43}$.

Em suma, tais fatos mostram que fatores econômicos provavelmente interferiram de forma positiva na admissão do forro Luís Cardoso em tal instituição. O que indica que a regra nem sempre era cumprida com precisão dentro do espaço colonial pernambucano e, em particular, na Ordem Terceira de São Francisco do Recife. Não existiu de fato no Pernambuco setecentista imobilidade social. Cada qual buscou, a sua maneira, melhor se apropriar das diversas oportunidades que a inserção em determinada teia de relações permitiu. A sociedade era hierarquizada, mas, ao mesmo tempo, dinâmica. Isso fez com que muitos homens de cor se beneficiassem das redes de sociabilidades, burlando a regra e obtendo prestígios. As estratégias usadas em suas atuações sociais, políticas e econômicas foram diárias e diversas. 


\section{Notas}

\footnotetext{
${ }^{1}$ Para uma melhor compreensão do uso do termo pardo em Pernambuco: $c f$ : BEZERRA, Janaína Santos. A fraude da tez branca: a integração de indivíduos e famílias pardas na elite colonial pernambucana (XVIII) .2016. 323 f. : il. Tese de Doutorado em História(Universidade Federal de Pernambuco), Recife.

${ }^{2}$ FARIA, Sheila de Castro. A Colônia em movimento. Rio de Janeiro: Nova Fronteira, 1998. p.158

3 AHU_ACL_CU_015, cx.76. [ant. 1754, julho, 29, Pernambuco], D.6377

${ }^{4}$ AHU_ACL_CU_015, cx.76. [ant. 1754, julho, 29, Pernambuco], D.6377

${ }^{5}$ PESSOA, Raimundo Agnelo Soares. Gente sem sorte: os mulatos no Brasil colonial.Tese de doutorado (Programa de Pós-Graduação em História da Faculdade de História, Direito e Serviço Social da Universidade Estadual Paulista "Júlio de Mesquita Filho") Doutorado em História. Franca, 2007. 232f.p.11

${ }^{6}$ BLUTEAU, Raphael. Vocabulário português e latino. Coimbra: Colégio das Artes da Companhia de Jesus, 1712-1727. v. 5, p. 730.

${ }^{7}$ XAVIER, Ângela Barreto e HESPANHA, António Manuel. A representação da sociedade e do poder. in MATTOSO, José. História de Portugal. Volume 4. O antigo Regime (1620-1807). Lisboa, Editorial Estampa. p. 131

${ }^{8}$ Ibid. p. 132

$9{ }^{9}$ SOUZA,Fernando Prestes de. Milicianos pardos em São Paulo: cor, identidade e política (1765-1831).
} Dissertação de Mestrado em História(Programa de Pós-graduação em História da Universidade Federal do Paraná).Curitiba, 2011.192f. p.89

${ }^{10}$ SOUZA, George F. Cabral de. Tratos e Mofatras: o grupo mercantil do Recife colonial(1654-1756). Recife:UFPE, 2012.p.162

${ }^{11}$ FRAGOSO, João. A nobreza da República: notas sobre a formação da primeira elite senhorial do Rio de Janeiro (séculos XVI e XVII). Topoi, Rio de Janeiro, nº 1, pp. 45-122.

${ }^{12}$ Idem

${ }^{13}$ PESSOA, Raimundo Agnelo Soares. Op. Cit. p.31-32

1414 SILVA, Maria Beatriz Nizza da. Ser nobre na colônia. Ed. Unesp. São Paulo, 2005. p. 132

${ }^{15}$ Cf. HESPANHA, Antônio Manuel. Op. Cit. 2005. Ver também: GUEDES, Roberto. Op. Cit. 2006.

${ }^{16}$ RÊGO, João de Figueirôa, OLIVAL, Fernanda. Op.cit. p.128-129

17 Idem

${ }^{18}$ MONTEIRO, Nuno Gonçalo. Elites locais e mobilidade social em Portugal nos finais do Antigo Regime. texto apresentados ao Seminário de História do ICS (Outubro de 1996) e ao $16 .^{\circ}$ Encontro da Associação Portuguesa de História Económica e Social em Novembro de 1996.análise social. vol. XXXII(141),1997(2º335368 , p.344-345

${ }^{19}$ RUSSELL-WOOD. A. J. R. op. Cit. p.119.

${ }^{20}$ Idem.

${ }^{21}$ Idem.

22 Ibid. p.120-121.

${ }^{23}$ HESPANHA, Antônio Manuel. Governo, elites e competência social: sugestões para um entendimento renovado da história das elites. In: BICALHO, Maria Fernanda; FERLINI, Vera Lúcia Amaral (orgs.). Modos de Governar. Alameda. São Paulo, 2005.p.43-44

${ }^{24}$ SOARES, Márcio de Sousa. Pretos e Pardos na fronteira do Império: Hierarquias e mobilidade social de libertos na capitania de Goiás(século XVIII). Trabalho apresentado no $4^{\circ}$ Seminário de Pesquisa do Instituto de Ciências da Sociedade e Desenvolvimento Regional, da Universidade Federal Fluminense - UFF, realizado em Campos dos Goytacazes-RJ, Brasil, em março de 2010.p.9

2525 ANDRADE, Manuel Correia de Oliveira; FRANDES, Eliane Moury; CAVALCANTE, Sandra Melo( Org)

Tempo dos Flamengos e outros tempo: Brasil século XVII. Brasília: CNPq; Recife: Fundaj, Ed. Massangana, 1999.p.255-256

${ }^{26}$ Idem

${ }^{27}$ Idem

${ }^{28}$ Ibid. p. 262

${ }^{29}$ Para mais informações sobre o surgimento da ordem de São Francisco ver: NETO, João Cabral de Melo. A Capela Dourada, símbolo do poder dos homens de negócio da praça. PUC- RIO- Certificação digital $n^{\circ}$ 0610626/CA.p. 83-117

${ }^{30}$ ANDRADE, M. C. de Oliveira; FRANDES, E. M.; CAVALCANTE, S. M.(Org.). Op. Cit. p.262 


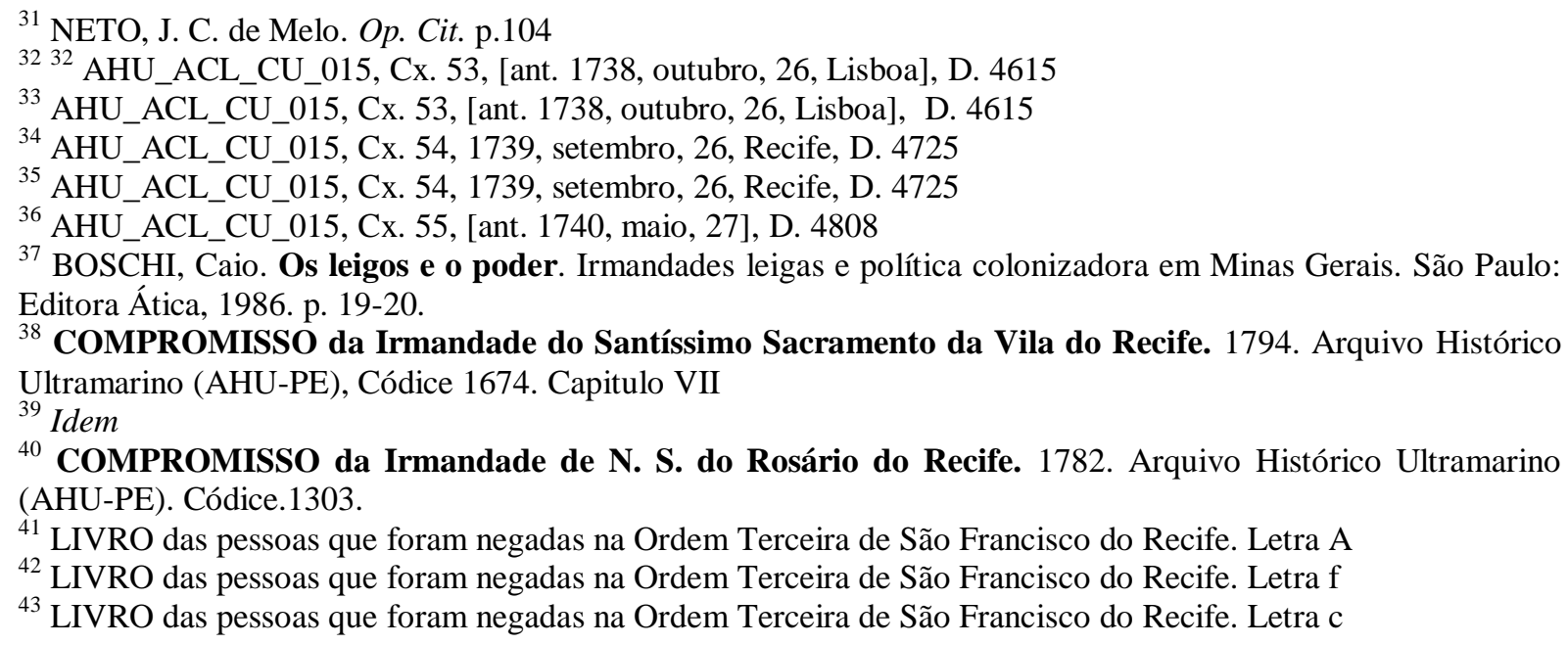

\section{Referências Bibliográficas}

ANDRADE, Manuel Correia de Oliveira; FRANDES, Eliane Moury; CAVALCANTE, Sandra Melo( Org) Tempo dos Flamengos e outros tempo: Brasil século XVII. Brasília: CNPq; Recife: Fundaj, Ed. Massangana, 1999.

BEZERRA, Janaína Santos. A fraude da tez branca: a integração de indivíduos e famílias pardas na elite colonial pernambucana (XVIII) .2016. 323 f. : il. Tese de Doutorado em História(Universidade Federal de Pernambuco), Recife.

BLUTEAU, Raphael. Vocabulário português e latino. vol. 5. Coimbra: Colégio das Artes da Companhia de

Jesus, 1712-1727.

BOSCHI, Caio. Os leigos e o poder. Irmandades leigas e política colonizadora em Minas Gerais. São Paulo: Editora Ática, 1986.

FARIA, Sheila de Castro. A Colônia em movimento. Rio de Janeiro: Nova Fronteira, 1998.

FRAGOSO, João. A nobreza da República: notas sobre a formação da primeira elite senhorial do Rio de Janeiro (séculos XVI e XVII). Topoi, Rio de Janeiro, no 1.pp. 45-122. SILVA, Maria Beatriz Nizza da. Ser nobre na colônia. Ed. Unesp. São Paulo, 2005.

HESPANHA, Antônio Manuel. Governo, elites e competência social: sugestões para um entendimento renovado da história das elites. In: BICALHO, Maria Fernanda; FERLINI, Vera Lúcia Amaral (orgs.). Modos de Governar. Alameda. São Paulo, 2005.

PESSOA, Raimundo Agnelo Soares. Gente sem sorte: os mulatos no Brasil colonial.Tese de doutorado (Programa de Pós-Graduação em História da Faculdade de História, Direito e Serviço Social da Universidade Estadual Paulista "Júlio de Mesquita Filho") Doutorado em História. Franca, 2007. 232f. 
XAVIER, Ângela Barreto e HESPANHA, António Manuel. A representação da sociedade e do poder. in MATTOSO, José. História de Portugal. Volume 4. O antigo Regime (16201807). Lisboa, Editorial Estampa.

MONTEIRO, Nuno Gonçalo. Elites locais e mobilidade social em Portugal nos finais do Antigo Regime. texto apresentados ao Seminário de História do ICS (Outubro de 1996) e ao 16..$^{\circ}$ Encontro da Associação Portuguesa de História Económica e Social em Novembro de 1996.análise social. vol. XXXII(141),1997(2º)335-368, p.344-345

NETO, João Cabral de Melo. A Capela Dourada, símbolo do poder dos homens de negócio da praça. PUC- RIO- Certificação digital nº 0610626/CA.

SOUZA,Fernando Prestes de. Milicianos pardos em São Paulo: cor, identidade e política (1765-1831). Dissertação de Mestrado em História(Programa de Pós-graduação em História da Universidade Federal do Paraná).Curitiba, 2011.192f.

SOUZA, George F. Cabral de. Tratos e Mofatras: o grupo mercantil do Recife colonial(1654-1756). Recife:UFPE, 2012.

SOARES, Márcio de Sousa. Pretos e Pardos na fronteira do Império: Hierarquias e mobilidade social de libertos na capitania de Goiás(século XVIII). Trabalho apresentado no $4^{\circ}$ Seminário de Pesquisa do Instituto de Ciências da Sociedade e Desenvolvimento Regional, da Universidade Federal Fluminense - UFF, realizado em Campos dos Goytacazes-RJ, Brasil, em março de 2010.

\section{Manuscritos}

AHU_ACL_CU_015, cx.76. [ant. 1754, julho, 29, Pernambuco], D.6377

AHU_ACL_CU_015, Cx. 53, [ant. 1738, outubro, 26, Lisboa], D. 4615

AHU_ACL_CU_015, Cx. 54, 1739, setembro, 26, Recife, D. 4725

AHU_ACL_CU_015, Cx. 55, [ant. 1740, maio, 27], D. 4808

COMPROMISSO da Irmandade do Santíssimo Sacramento da Vila do Recife. 1794. Arquivo Histórico Ultramarino (AHU-PE), Códice 1674. Capitulo VII

COMPROMISSO da Irmandade de N. S. do Rosário do Recife. 1782. Arquivo Histórico Ultramarino (AHU-PE). Códice.1303.

LIVRO das pessoas que foram negadas na Ordem Terceira de São Francisco do Recife. (XVIII). 